\title{
Inadvertent Perioperative Hypothermia and Important Risk Factors during Major Abdominal Surgeries
}

\author{
Gonul Sagiroglu1, Gozde Argunsah Ozturk1, Ayse Baysal2 and Fatma Nesrin Turan³ \\ 1Department of Anesthesiology, Faculty of Medicine, Trakya University, Edirne, Turkey \\ 2Department of Anesthesiology, Pendik Bolge Hospital, Pendik, Istanbul, Turkey \\ ${ }^{3}$ Department of Biostatistics and Medical Informatics, Faculty of Medicine, Trakya University, Edirne, Turkey
}

\begin{abstract}
Objective: A relation between inadvertent perioperative hypothermia and possible important risk factors during major abdominal surgeries was investigated.

Study Design: Cross-sectional descriptive study.

Place and Duration of Study: Trakya University Hospital, Edirne, Turkey during 2016-2018.

Methodology: Five hundred and twenty-nine patients undergoing major abdominal surgey were divided into two groups depending on postoperative body core temperature (CTM) by the use of tympanic membrane measurement. Patients with a temperature of less than $36^{\circ} \mathrm{C}$ indicated hypothermia group; whereas, patients with a temperature between 36 and $37.5^{\circ} \mathrm{C}$ indicated normothermia group. The parameters that were considered as risk factors for hypothermia include; baseline characteristics, American Society of Anesthesiologists (ASA) status, comorbidities, operative type, duration of surgery, patient and operative room temperatures, intraoperative hemodynamic parameters, transfusion of fluids and packed red blood cells (PRBCs), labaratory data, and adverse events. Correlation between these parameters and inadvertent hypothermia was sought. A p-value of less than 0.05 was considered statistically significant.

Results: The risk factors that showed a correlation with hypothermia include: male gender, advanced age, high ASA scores, smoking, prolonged duration of operation, transfusion of fluids and PRBCs $(p<0.05)$. In hypothermia group, duration of operation time was longer, need for transfusion was greater, hematocrit and hemoglobin values were lower than Normothermia Group of patients $(p<0.05)$. Hypothermia was detected in $335(63.3 \%)$ of patients.

Conclusion: In this study, important risk factors for inadvertent hypothermia were found as; male gender, advanced age, high ASA scores, smoking, prolonged duration of operation, transfusion of fluids and/or PRBCs.
\end{abstract}

Key Words: Hypothermia, General anesthesia, Body temperature.

How to cite this article: Sagiroglu G, Ozturk GA, Baysal A, Turan FN. Inadvertent perioperative hypothermia and important risk factors during major abdominal surgeries. J Coll Physicians Surg Pak 2020; 30(2):123-128.

\section{INTRODUCTION}

Inadvertent perioperative hypothermia, defined as body core temperature measurement (CTM) at a level below $36^{\circ} \mathrm{C}$, has been reported more frequently in various risk factors. 1-3 Measurement of body temperature using the tympanic temperature measurement (TTM) represents a standard non-invasive method, which best approximates CTM. 1

Early detection of inadvertent hypothermia and monitoring of CTM for the provision of normothermia in perioperative period is very important.1-3 International anesthesia societies such as; the National Institute of Health and Care Excellence (NICE) and American Society of Anesthesiology (ASA) recommend perioperative

Correspondence to: Dr. Gonul Sagiroglu, Department of Anesthesiology, Faculty of Medicine, Trakya University, Edirne, Turkey

E-mail: gonulsagiroglu45@gmail.com

Received: August 16, 2019; Revised: December 09, 2019;

Accepted: January 11, 2020 temperature monitoring and active heating of patients as standard practice..$^{4,5}$

In this study, during major abdominal operations under general anesthesia (GA), an investigation was performed to detect a correlation between demographic characteristics of patients and the incidence of inadvertent perioperative hypothermia. Additionally, a correlation between inadvertent perioperative hypothermia and other variables, such as surgical duration and type of surgery, operating room temperature (ORT), hemodynamic parameters, total diuresis, bleeding, need for fluid and blood transfusions, hematocrit and hemoglobin values, arterial blood gas analysis, postoperative adverse events, were investigated.

\section{METHODOLOGY}

A descriptive, cross-sectional study was conducted from September 2016 to February 2018, in accordance with the Helsinki Declaration and after the Ethical Research Committee approval (2016/198,BAEK-13/27). Informed consents were obtained from all patients. In this study of 
529 patients, inclusion criteria for enrollment included; the ASA physical status classification of II-III, ages between 21 and 86 years and undergoing elective major abdominal (gynecology, urology, general) surgeries for a duration of at least one hour under GA. Exclusion criteria for study included; emergency operations, GA operations under one hour, neuroleptic malignant syndrome, malignant hyperthermia, neurologic disease, thyroid disease, renal and liver dysfunction, ear exam revealing ear infection, fuse or wound.

CTM value was followed by anesthesia doctors or technicians using infrared tympanic membrane thermometer. ${ }^{6}$ The American Society of Perianesthesia Nurses (ASPAN) recommends TTM in the hypothermic prevention guide. ${ }^{5}$ The ambient ORT was recorded in every case by an anesthesiology resident. No active or passive heating method was applied to any patient during this study. CTM value less than $36^{\circ} \mathrm{C}$ was considered as hypothermia. ${ }^{2}$ According to TTM in postperative period, patients with CTM value of less than $36^{\circ} \mathrm{C}$ were included into hypothermia group; whereas, patients with CTM value between $36^{\circ} \mathrm{C}$ or $37.5^{\circ} \mathrm{C}$ were included into normothermia group.

Premedication was not in this study protocol; however, some patients received a combination of intramuscular midazolam and atropine sulfate before surgery. The number of patients who underwent premedication was recorded.

In the preoperative period, demograhic data including gender, age, height, weight, BMI classification 7 , ASA and smoking were collected. Preoperatively, the hemodynamic parameters such as blood pressure (BP), heart rate $(\mathrm{HR})$, peripheral oxygen saturation $\left(\mathrm{SpO}_{2}\right)$ as well as CTM, premedication status, type of surgery were also recorded. Intraoperative parameters that were collected include; operation time, hemodynamic parameters that were collected at various time points. The time points where hemodynamic parameters were collected include; before anesthesia induction (baseline) and after anesthesia induction at 0 minute and 15 minutes apart $(0,15,30,45,60,75,90$ and $105 \mathrm{~min}), \mathrm{ORT}$, diuresis, blood loss, requirement for fluid and packed red blood cells (PRBCs) transfusions, hematocrit and hemoglobin values. Postoperatively, arterial blood gas sample values including $\mathrm{pH}$, partial pressure of oxygen in arterial blood, partial pressure of carbon dioxide were analysed to provide respiratory and metabolic effects of hypothermia. Other parameters that were collected include; hematocrit and hemoglobin values, adverse events such as incidence of shivering, nausea, vomiting and others. During the induction of GA, propofol, fentanyl, rocuronium bromide were administered intravenously. Maintenance of anesthesia was provided with inhaled anesthesia of sevoflurane. Fluids were administered without warming, however, PRBCs were administered after being warmed to $36^{\circ} \mathrm{C}$ with a blood warmer.
Statistical analysis was performed using SPSS for Windows 22.0 (SPSS Inc, Chicago, IL, USA). Based on a previous study, a total of 529 patients were calculated to show a temperature difference of $1^{\circ} \mathrm{C}$ and this could be determined at the level of 0.8 power and 0.05 significance. 8 In this study, the sample size was based according to the previous study. The normal distribution of variables were examined using Shapiro-Wilk test. For variables without normal distribution, the differences were compared using One-way ANOVA and Student's t-test. For variables without normal distribution, the differences were compared using Mann-Whitney U-test, Kruskal-Wallis test. Chi-Square, Fisher's Exact tests were performed for categorical variables. A p-value of less than 0.05 was regarded as statistically significant.

\section{RESULTS}

The patients were divided into two groups according to CTM as hypothermia group $(n=335)$ and normotermia group $(n=194)$. The demographic data of the groups are presented in Table I. The most significant differences between groups related to age, gender, ASA status, smoking, duration of operations and crystalloid or total fluid resuscitation, are shown in Table I. There was a statistically significant correlation between smoking and

Table I: Comparison of demographic data and operation characteristics of patients.

\begin{tabular}{|c|c|c|c|}
\hline Variables & $\begin{array}{l}\text { Hypothermia } \\
\text { Group }(n=335)\end{array}$ & $\begin{array}{l}\text { Normothermia } \\
\text { Group }(n=194)\end{array}$ & $\mathrm{p}$-value \\
\hline Gender, n (\%) & & & $0.023^{*}$ \\
\hline Male & $109(32.5)$ & $45(23.2)$ & \\
\hline Female & $226(67.5)$ & $149(76.8)$ & \\
\hline $\begin{array}{l}\text { Age, (years) } \\
<0.0001^{*}\end{array}$ & $58.91 \pm 12.35$ & $52.18 \pm 11.02$ & \\
\hline Height $(\mathrm{cm})$ & $164.43 \pm 0.45$ & $164.41 \pm 0.57$ & 0.93 \\
\hline Weight (kg) & $77.43 \pm 0.8$ & $76.83 \pm 1.1$ & 0.403 \\
\hline Body mass index $\left(\mathrm{kg} / \mathrm{m}^{2}\right)$ & $28.74 \pm 0.31$ & $28.46 \pm 0.4$ & 0.749 \\
\hline Body mass index, $\mathrm{n}(\%)$ & & & 0.925 \\
\hline Underweight & $1(0.3)$ & $1(0.5)$ & \\
\hline Normal weight & $95(28.4)$ & $51(26.3)$ & \\
\hline Overweight & $116(34.6)$ & $75(38.7)$ & \\
\hline Class I obesity & $73(21.8)$ & $42(21.6)$ & \\
\hline Class II obesity & $38(11.3)$ & $18(9.3)$ & \\
\hline Class III obesity & $12(3.6)$ & $7(3.6)$ & \\
\hline ASA classification, $\mathrm{n}(\%)$ & & & $0.004^{*}$ \\
\hline II & $260(77.6)$ & $170(87.6)$ & \\
\hline III & $75(22.4)$ & $24(12.4)$ & \\
\hline Smoking; n (\%) & $70(20.9)$ & $66(34)$ & $0.001^{*}$ \\
\hline Premedication status; n (\%) & $24(7.2)$ & $13(6.7)$ & 0.840 \\
\hline Surgery type & & & 0.05 \\
\hline General surgery & $167(49.9)$ & $79(40.7)$ & \\
\hline Gynecology & $150(44.8)$ & $108(55.7)$ & \\
\hline Urology & $18(5.4)$ & $7(3.6)$ & \\
\hline Duration of surgery (min) & $184.88 \pm 71.72$ & $154.36 \pm 63.54$ & $<0.0001^{*}$ \\
\hline Operating room temperature $\left({ }^{\circ} \mathrm{C}\right)$ & $21.74 \pm 0.69$ & $21.76 \pm 0.65$ & 0.721 \\
\hline Crystalloid resuscitation $(\mathrm{mL})$ & $3666.27 \pm 1826.31$ & $2915.98 \pm 1464.11$ & $<0.0001^{*}$ \\
\hline Total fluid resuscitation (mL) & $3775.07 \pm 1941.97$ & $2967.53 \pm 1493.31$ & $<0.0001^{*}$ \\
\hline
\end{tabular}


preoperative and postoperative CTM $(r=-0.168 ; p<0.0001$, $r=-0.123 ; p=0.005)$. In Figure 1, time-dependent correlations between CTM values and smoking are shown.

At all collected time points, the groups were compared for BP (systolic, diastolic, mean) and HR values and in comparison to preoperative values, a significant reduction was observed for all four parameters at all time points $(p<0.0001)$. For both groups of patients, $\mathrm{SpO}_{2}$ values were higher at each collected time during the operation in comparison to preoperative baseline values $(p<0.0001)$.

Time-dependent correlations between ORS, diuresis, bleeding amount and replacement therapies with CTM are presented in Table II. A correlation between CTM values and surgical types revealed that a reversed weak correlation was found with gynocologic $(r=0.100$; $p=0.022)$ and general surgery operations $(r=-0.087$; $p=0.046$ ) postoperatively. However, Figure 2 provides data that, there was a weak correlation between CTM values and urologic surgical operations $(r=0.093$; $\mathrm{p}=0.033$ ) preoperatively (Figure 2 ).

A correlation between $\mathrm{BMI}$ and CTM values was not statistically significant $(p>0.05)$. When examining the changes in CTM values related to ASA status; CTM of patients in ASA-II class in preoperative $(r=-0.135 ; p=0.002)$, and postoperative $(r=-0.182 ; p<0.0001)$ periods, were statistically significantly higher in comparison to the patients with ASA-III class.

There was a very weak and statistically significant correlation between operation times and intraoperative CTM values at the time point of $105^{\text {th }}$ minute postoperatively $(r=-0.129 ; p=0.004, r=-0.225 ; p<0.0001$, respectively $)$.

Time-dependent correlations between CTM values and the values of hemoglobin and hematocrit at the collected times preoperatively and postoperatively are presented in Table III. There was significant correlations between CTM values and hemoglobin and hematocrit values at preoperative, intraoperative $105^{\text {th }}$ minute and postoperative values $(p<0.05)$.

There was no statistically significant correlation between ORT and the compared parameters including surgery types, diuresis, fluid and blood resuscitations. In contrast, there was a statistically highly significant reversed correlation between ORT and blood loss $(r=-0.0174 ; p<0.0001)$.

The comparison of arterial blood gas analysis of hypothermia and normotermia groups revealed no significant

Table II: Time-dependent correlations between body core temperature with operating room temperature, diuresis, bleeding amount and replacement therapies.

\begin{tabular}{|c|c|c|c|c|c|c|c|c|c|c|}
\hline \multirow[t]{2}{*}{ Time (min) } & \multicolumn{2}{|c|}{$\begin{array}{l}\text { Operating room } \\
\text { temperature }\end{array}$} & \multicolumn{2}{|c|}{ Total diuresis } & \multicolumn{2}{|c|}{ Total blood loss } & \multicolumn{2}{|c|}{$\begin{array}{l}\text { Total fluid } \\
\text { resuscitation }\end{array}$} & \multicolumn{2}{|c|}{$\begin{array}{l}\text { Total blood } \\
\text { resuscitation }\end{array}$} \\
\hline & $r$ & $p$ & $r$ & $\mathrm{p}$ & $r$ & $\mathrm{p}$ & $r$ & $p$ & $r$ & $p$ \\
\hline Preoperative & 0.010 & $0.017^{*}$ & -0.047 & 0.295 & -0.074 & 0.088 & -0.056 & 0.196 & -0.096 & 0.028 \\
\hline \multicolumn{11}{|l|}{ Intraoperative } \\
\hline 0 & 0.001 & 0.996 & -0.022 & 0.621 & -0.002 & 0.954 & -0.031 & 0.482 & -0.004 & 0.921 \\
\hline 15 & 0.058 & 0.187 & -0.043 & 0.334 & 0.022 & 0.613 & -0.017 & 0.695 & -0.044 & 0.309 \\
\hline 30 & 0.033 & 0.454 & -0.058 & 0.190 & 0.026 & 0.544 & -0.026 & 0.558 & -0.016 & 0.717 \\
\hline 45 & 0.034 & 0.439 & -0.038 & 0.395 & 0.038 & 0.383 & -0.018 & 0.681 & -0.013 & 0.758 \\
\hline 60 & 0.051 & 0.246 & -0.037 & 0.409 & 0.030 & 0.490 & -0.019 & 0.658 & -0.005 & 0.910 \\
\hline 75 & 0.037 & 0.404 & -0.031 & 0.482 & 0.030 & 0.490 & -0.023 & 0.606 & -0.002 & 0.964 \\
\hline 90 & 0.054 & 0.222 & -0.031 & 0.492 & 0.016 & 0.724 & -0.022 & 0.624 & -0.010 & 0.822 \\
\hline 105 & 0.021 & 0.639 & -0.049 & 0.294 & -0.010 & 0.825 & -0.068 & 0.134 & -0.046 & 0.311 \\
\hline Postoperative & 0.002 & 0.932 & -0.187 & $<0.0001^{*}$ & -0.187 & $<0.0001^{*}$ & -0.187 & $<0.0001^{*}$ & -0.237 & $<0.0001^{*}$ \\
\hline
\end{tabular}

${ }^{*} p<0.05$, Statistically significant.

Table III: Time-dependent correlations of body core temperature (CTM) with hemoglobin and hematocrit values in preoperative and postoperative periods.

\begin{tabular}{|c|c|c|c|c|c|c|c|c|}
\hline \multirow[t]{2}{*}{ Time (min) } & \multicolumn{2}{|c|}{$\begin{array}{c}\text { Preoperative hemoglobin } \\
\text { values }\end{array}$} & \multicolumn{2}{|c|}{$\begin{array}{l}\text { Postoperative hemoglobin } \\
\text { values }\end{array}$} & \multicolumn{2}{|c|}{$\begin{array}{c}\text { Preoperative hematocrit } \\
\text { values }\end{array}$} & \multicolumn{2}{|c|}{$\begin{array}{l}\text { Postoperative hematocrit } \\
\text { values }\end{array}$} \\
\hline & $r$ & $p$ & $r$ & $\mathrm{p}$ & $r$ & $\mathrm{p}$ & $r$ & $p$ \\
\hline Preoperative & 0.171 & $<0.0001^{*}$ & 0.133 & 0.166 & 0.169 & $<0.0001^{*}$ & 0.149 & 0.121 \\
\hline \multicolumn{9}{|l|}{ Intraoperative } \\
\hline 0 & 0.042 & 0.332 & 0.023 & 0.812 & 0.050 & 0.248 & 0.054 & 0.575 \\
\hline 15 & 0.046 & 0.288 & 0.197 & $0.039^{*}$ & 0.031 & 0.481 & 0.255 & 0.007 \\
\hline 30 & 0.055 & 0.207 & 0.289 & $0.002^{*}$ & 0.046 & 0.286 & 0.357 & $<0.0001^{*}$ \\
\hline 45 & 0.053 & 0.221 & 0.279 & $0.003^{*}$ & 0.043 & 0.325 & 0.327 & $<0.0001^{*}$ \\
\hline 60 & 0.045 & 0.299 & 0.302 & $0.001^{*}$ & 0.035 & 0.426 & 0.342 & $<0.0001^{*}$ \\
\hline 75 & 0.057 & 0.194 & 0.303 & $0.001^{*}$ & 0.038 & 0.387 & 0.313 & $0.001^{*}$ \\
\hline 90 & 0.047 & 0.286 & 0.259 & $0.006^{*}$ & 0.025 & 0.573 & 0.261 & $0.006^{*}$ \\
\hline 105 & 0.090 & $0.046^{*}$ & 0.263 & $0.006^{*}$ & 0.070 & 0.123 & 0.250 & $0.009^{*}$ \\
\hline Postoperative & 0.123 & $0.005^{*}$ & 0.159 & 0.099 & 0.131 & $0.003^{*}$ & 0.158 & 0.101 \\
\hline
\end{tabular}

${ }^{*} p<0.05$, Statistically significant. 


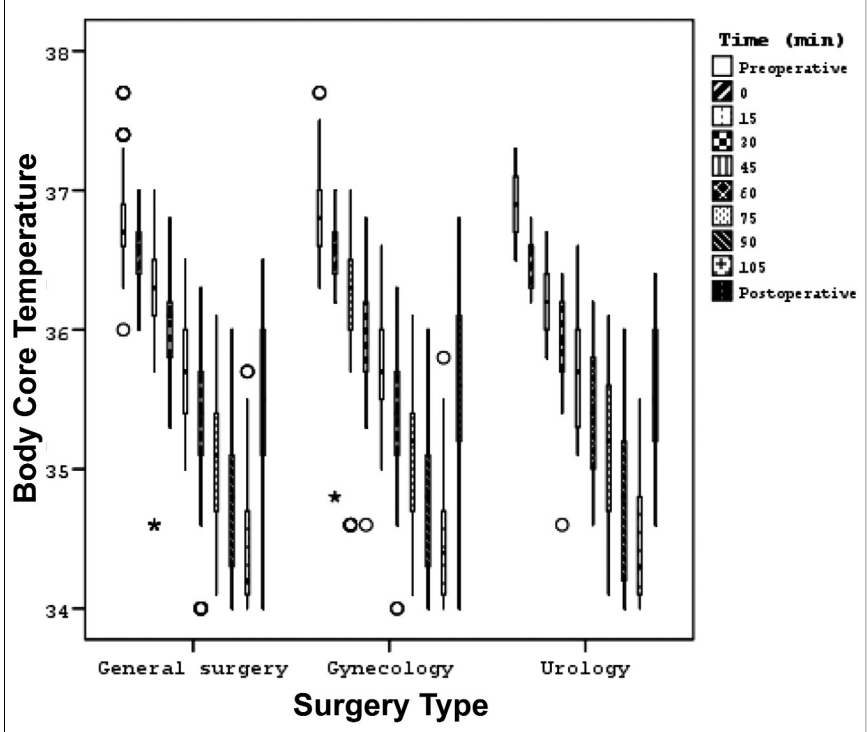

Figure 1: Plot data of time-dependent correlations between body core temperature (CTM) and smoking.

differences between groups. The incidence of postoperative shivering was observed in a total of 203 $(38.4 \%)$ patients; and in hypothermia versus normothermia group of patients, these incidences were 145 $(43.3 \%)$ versus $58(29.9 \%), p=0.002$, respectively. The incidence of postoperative nausea/vomiting was observed in 4 (8\%) patients. The incidence was not different between groups [2 $(0.6 \%)$ versus $2(1 \%)$, $p=0.579]$.

A correlation analysis between age and shivering revealed a weak reversed correlation between them $(r=-0.239$, $p<0.0001)$. The ORT showed no effect on postoperative shivering $(r=-0.045 ; p=0.298)$ and nausea/vomiting $(r=-0.007 ; p=0.872)$.

\section{DISCUSSION}

The predisposing risk factors in the development of perioperative inadvertent hypothermia in major abdominal operations showed that male gender, advanced age, high ASA, smoking, prolonged duration of operation, transfusion of fluids and/or PRBCs are statistically significant risk factors for inadvertent hypothermia. Hypothermia was detected in 335 (63.3\%) of all patients. In hypothermia group, duration of operation time was longer, need for fluid and blood product transfusions was greater and hematocrit and hemoglobin values were lower than normothermia group.

Although it is very difficult to prevent involuntary perioperative hypothermia during surgery, it is a predetermined and preventable condition. NICE recommends heating of patients with CTM value of less than $36^{\circ} \mathrm{C} .4$ In the first hour after the GA induction, the average CTM value drop has been reported as $1^{\circ} \mathrm{C}$ and $\mathrm{CTM}$ value has been recorded as $35.8^{\circ} \mathrm{C}$. This observation provides information that keeping normotermia is clinically

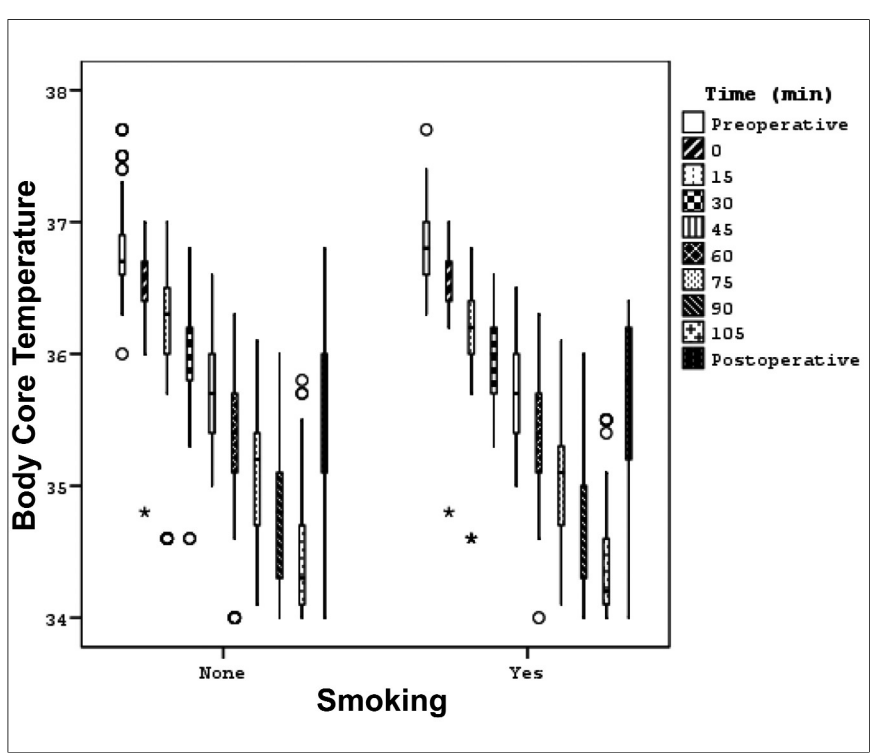

Figure 2: Plot data of time-dependent correlations between body core temperature (CTM) and surgical types.

important. ${ }^{9}$ Although severe complications of perioperative hypothermia have been reported in many studies, temperature monitoring and management in clinical practice have not been introduced. In a random survey on a total of 8,083 patients, perioperative temperature monitoring was used in $19 \%$ of the patients and only $38 \%$ of the whole group of patients received active heating. ${ }^{3}$

In a national cross-sectional study including a total of 3,132 patients, the incidence of inadvertent hypothermia was detected in $44.3 \%$ of the patients. 6 The incidence of hypotermia varies in different studies between $30 \%$ and $41 \% .10,11$ In this study, perioperative hypothermia frequency was higher because of the reason that no heating was considered during surgeries and administration of fluid were without heating, however, blood products were warmed to $36^{\circ} \mathrm{C}$ prior to administration to the patients.

There are different opinions associated with the gender factor in the peroperative hypothermia. In a study, no correlation between gender and intraoperative hypothermia was found in abdominal surgeries under GA. ${ }^{12}$ However, another study showed that gender is a strong CTM indicator and the perioperative heat loss in men is higher than women and a similar result was found in this study. ${ }^{13}$ There are multiple factors that influence the development of hypothermia with advanced age. Thermoregulatory vasoconstriction occurs in lower CTM. The ratio between body weight and body surface area increases. Muscle mass and subcutaneous fat tissue decrease, and are responsible for thermogenesis without shivering. Metabolic heat production rate diminishes and all these factors contribute to the development of hypothermia.11,12,14,15 A previous study pointed out that advanced age is an important risk factor 
in the development of postoperative hypothermia. ${ }^{12}$ The duration of hypothermia in elderly patients was found to be longer in PACU. ${ }^{16}$ Another study considered the use of continuous CTM during surgery. ${ }^{17}$ This study shows similar findings by a correlation between age with inadvertent hypothermia and this has been supported by previous studies. $7,8,12,13$

Regarding ASA status correlation with perioperative hypothermia, there has been some conflicting data in the literature.13,15,17 While some research works support that there is no correlation, a study advocate that the decrease in CTM is found to be more in patients with higher ASA scores; and findings of the present study show similar results. ${ }^{18}$ In this study, the incidence of hypothermia in patients with ASA II status was less than those of ASA III status.

For the patients with long operation time, hypothermia is more likely outcome. ${ }^{15}$ For this reason, it is recommended to actively heat all patients and follow perioperative CTM for surgery that lasts longer than thirty minutes. ${ }^{17}$ In the first hour of GA, the CTM falls $1.6 \pm 0.3^{\circ} \mathrm{C}$ and in the second and third hours, the CTM drops further at a level of $1.1 \pm 0.3^{\circ} \mathrm{C} .19$ The prevalence of hypothermia 1 or 4 hours after induction of GA was reported as: $17.8 \%$, $36.2 \%, 42.5 \%, 44.1 \%$, respectively. 6 In this research, in comparison to preoperative values, in all surgical operations, significant decrease in CTM was recorded in all time periods intra- and postoperatively. These findings are also supported in previous studies. 6,13

Even if ambient temperature is controlled by room thermostats, imbalances can be experienced at optimum temperature settings. ${ }^{12,18}$ In low ORT, the tendency to hypothermia increases. ${ }^{15}$ In a study, cold operating table, low ORT and cold sterilisation solutions was shown to cause a significant decrease in CTM. ${ }^{12}$ Therefore, NICE recommends keeping the ORT between $21-24^{\circ} \mathrm{C}$. In this study, the average ORT in the operating theatre was found to follow the NICE guidelines. ${ }^{4}$

The primary cause of postoperative morbidity is cardiac complications; and prolonged hypothermia can cause cellular damage with decreased perfusion.1,2,15 In this study, hypothermia had no significant effect on hemodynamic parameters. However, the decrease in BP, HR values in intraoperative and postoperative periods was evident compared to the preoperative basal value. In fact, BP values in hypothermic cases were expected to be higher. The time-dependent fall in the BP can be explained by inhibition of vasoconstriction by anesthetic agents administered during GA induction and maintenance.

Since involuntary hypothermia leads to a significant increase in the need for transfusion, achieving normo-thermia during surgery helps reduce perioperative blood loss. ${ }^{14}$ A study indicated that there is no positive correlation between surgical blood loss and transfusion need. ${ }^{9}$ In a meta-analysis involving 14 randomised controlled trials, even mild hypothermia is associated with surgical blood loss $(16 \%)$ and this has led to an increase need of blood product transfusion. 20 Here, three studies have been reviewed showing that fluids and blood products that were not heated to CTM cause with perioperative hypothermia.4,6,20 The risk of involuntary hypothermia is significantly increased with fluids which were greater than $1000 \mathrm{~mL}$ during surgeries. ${ }^{6}$ Studies suggest that fluids and blood products should be heated when administered at a rate greater than $500 \mathrm{~mL}$ per hour. 4,15 The degree of heating for these fluids has been reported as $38-40^{\circ} \mathrm{C} .3,4,14$

A correlation between CTM less than $37^{\circ} \mathrm{C}$ and the incidence of perioperative blood transfusions based on a multivariate logistic regression analysis was presented previously. ${ }^{15}$ However, the present findings show difference from another study that in their study an association between postoperative PRBC transfusions with hypothermia was not demonstrated; and they pointed out to a significant deterioration in $\mathrm{pH}$ balance after blood transfusions. ${ }^{21}$ In this study, surgical blood loss was higher in hypothermic patients and the need for fluid and PRBC transfusions was significantly higher. In this study, the operating room does not provide adequate warming of the patient and fluids because of the lack of necessary equipments. However, the PRBCs were warmed to $36^{\circ} \mathrm{C}$ prior to administration to the patients. In a previous study, it has been shown that even a mild degree of hypothermia of less than $1^{\circ} \mathrm{C}$ increases blood loss by $16 \%$ and increases the relative risk for transfusion by $22 \% .{ }^{20}$

Previous studies demonstrated that postoperative shivering increases oxygen consumption up to $40 \%$ and may cause hypoxia and acidosis. 5,15 In our study, the incidence of postoperative shivering was $38.4 \%$ of all patients and it was significantly higher in hypothermic patients $(43.3 \%, p=0.0023)$. A correlation betwen hypothermia and shivering has been reported previously.6,18,22 There is also a discussion that the use of inhalational anesthetic agents may produce more postoperative shivering than the use of intravenous anesthetic agents. ${ }^{22}$

\section{CONCLUSION}

The incidence of inadvertent hypothermia after major abdominal surgeries is high; and this finding is found to be related to several predisposing factors. Male gender, advanced age, ASA III, smoking, prolonged operation duration, fluid, and blood product transfusions are found to be predisposing factors in development of inadvertent hypothermia. In hypothermia group of patients, hematocrit and hemoglobin values were lower and the incidence of postoperative shivering was higher. TTM provides valuable data for CTM monitoring. 


\section{ETHICAL APPROVAL:}

Ethics Committee approval was received for this study from the Ethics Committee of Trakya University School of Medicine Hospital University's Ethics Review Committee (2016/198, TÜTF-BAEK 13/27).

\section{PATIENTS' CONSENT:}

Written informed consents were obtained from patients who participated in this study.

\section{CONFLICT OF INTEREST:}

Authors declared no conflict of interest.

\section{AUTHORS' CONTRIBUTION:}

GS, GAO, AB, FNT: Design, supervision, data collection and/or processing, analysis and/or interpretation, literature review, and critical review.

\section{REFERENCES}

1. Yi J, Liang $H$, Song $R$, Xia $H$, Huang $Y$. Maintaining intraoperative normothermia reduces blood loss in patients undergoing major operations: A pilot randomized controlled clinical trial. BMC Anesthesio/2018; 18:126.

2. Bilgin $H$. Inadverdent perioperative hypothermia. Turk $J$ Anaesthesiol Reanim 2017; 45:124-6.

3. Torossian A, TEMMP (Thermoregulation in Europe monitoring and managing patient temperature) study group. Survey on intraoperative temperature management. Europe Eur $J$ Anaesthesiol 2007; 24:668-75.

4. Clinical-Practice-Guidelines, the management of inadverten perioperative hypothermia in adults. National collaborating centre for nursing and supportive care commissioned by national institute for health and clinical excellence (NICE). ed. Philadelphia: Lippincott-Raven; 2008.

5. American society of perianesthesia nurses. Clinical guidelines for the prevention of unplanned perioperative hypothermia. $J$ Perianesth Nurs 2001; 16:305-14.

6. Yi J, Lei Y, Xu S, Si Y, Li S, Xia Z, et al. Intraoperative hypothermia and its clinical outcomes in patients undergoing general anesthesia: National study in China. PLoS One 2017; 12:e0177221.

7. Zafar S, Israr ul Haq, Butt AR, Shafiq F, Mirza HG, Ameed-urRehman. Correlation of endoscopic severity of gastroesophageal reflux disease (GERD) with body mass index (BMI). J Coll Physicians Surg Pak 2007; 17:72-5.

8. Kongsayreepong S, Chaibundit C, Chadpaibool J, Komoltri C, Suraseranivongse S, Suwannanonda P, et al. Predictor of core hypothermia and the surgical intensive care unit. Anesth Analg 2003; 96:826-33.
9. Ruetzler K, Kurz A. Consequences of perioperative hypothermia. Handb Clin Neurol 2018; 157:687-97.

10. Forbes SS, Stephen WJ, Harper WL, Loeb M, Smith R, Christoffersen EP, et al. Implementation of evidence-based practices for surgical site infection prophylaxis: Results of a pre- and postintervention study. J Am Coll Surg 2008; 207:336-41.

11. Yang L, Huang CY, Zhou ZB, Wen ZS, Zhang GR, Liu KX, et al. Risk factors for hypothermia in patients under general anesthesia: Is there a drawback of laminar airflow operating rooms? A prospective cohort study. Int J Surg 2015; 21:14-7.

12. Kim EJ, Yoon H. Preoperative factors affecting the intraoperative core body temperature in abdominal surgery under general anesthesia. An observational cohort. Clin Nurse Spec 2014; 28:268-76.

13. Panagiotis K, Maria $\mathrm{P}$, Argiri $\mathrm{P}$, Panagiotis $\mathrm{S}$. Is postanesthesia care unit length of stay increased in hypothermic patients? AORN J 2005; 81:379-82.

14. AORN. Guidelines for prevention of unplanned patient hypothermia. AORN J 2016; 103:314-5.

15. Sun Z, Honar H, Sessler DI, Dalton JE, Yang D, Panjasawatwong K, et al. Intraoperative core temperature patterns, transfusion requirement, and hospital duration in patients warmed with forced air. Anesthesiology 2015; 122:276-85.

16. Mendonça FT, Lucena MC, Quirino RS, Govêia CS, Guimarães GMN. Risk factors for postoperative hypothermia in the post-anesthetic care unit: A prospective prognostic pilot study. Rev Bras Anestesiol 2019; 69:122-30.

17. Castillo Monzón CG, Candia Arana CA, Marroquín Valz HA, Rodríguez FA, Benavides Mejía JJ, Alvarez Gómez JA. Temperature management during the perioperative period and frequency of inadvertent hypothermia in a general hospital. Colombian J Anesthesiol 2013; 41:97-103.

18. Taniguchi $Y$, Lenhardt R, Sessler DI, Kurz A. The effect of altering skin-surface cooling speeds on vasoconstriction and shivering thresholds. Anesth Analg 2011; 113:540-4.

19. Abelha FJ, Castro MA, Neves AM, Landeiro NM, Santos CC. Hypothermia in a surgical intensive care unit. BMC Anesthesiol 2005; 5:1-10.

20. Rajagopalan S, Mascha E, Na J, Sessler D. The effects of mild perioperative hypothermia on blood loss and transfusion requirement. Anesthesiology 2008; 108:71-7.

21. Williams B, Chriss E, Kaplan J, Cartron A, Taylor B, Gammie J, et al. Hypothermia, $\mathrm{pH}$, and postoperative red blood cell transfusion in massively transfused adult cardiac surgery patients: A retrospective cohort study. J Cardiothorac Vasc Anesth 2018; 32:1642-7.

22. Aldehayat G. Intraoperative dexmedetomidine administration at the end of surgery prevents post anesthetic shivering. Rawal Med J 2011; 36:1-5. 